\author{
Ivan Smirnov \\ iD https://orcid.org/0000-0003-3066-5591 \\ Uniwersytet Łódzki \\ Wydział Filologiczny \\ Instytut Rusycystyki \\ Zakład Językoznawstwa \\ 90-226 Łódź, ul. Pomorska 171/173 \\ i.smirnow.edu@gmail.com \\ https://doi.org/10.18778/8220-520-6.05
}

\title{
МЕТАФОРА КАК МЕХАНИЗМ РАЗРУШЕНИЯ ГЕНАЕРНЫХ СТЕРЕОТИПОВ
}

\section{Metaphor as a mechanism of invalidating gender stereotypes}

\author{
Metafora jako mechanizm burzenia stereotypów płci
}

\begin{abstract}
Резюме
В статье оспариваются теоретические постулаты гендерной мингвистики. В частности, ставится поА сомнение главенствующая в гендерных исслеАованиях андроцентрическая точка зрения. Исходным материалом Аля анализа послужили метафорические номинации, характеризующие мужчину в китайском языке. Приведенные на русском языке эквиваленты подтвержАают существование общих мотивационных установок, отраженных в китайском и русском языках. Альтернативный взгля на преАложенные репрезентативные схемы способствует разрушению устоявшихся стереотипов в гендерных исследованиях.
\end{abstract}

\section{Summary}

The article challenges the theoretical claims of gender linguistics. The androcentric point of view that is dominant in gender studies is especially challenged. The initial material for the analysis was the metaphorical nominations characterizing a male in Chinese. The equivalents given in Russian confirm the existence of common motivational attitudes reflected in the Chinese and Russian languages. An alternative view of the proposed representational schemes contributes to the rejection of stereotypes established in gender studies. 


\section{Streszczenie}

Artykuł poddaje krytyce teoretyczne postulaty lingwistyki płci. W szczególności kwestionowany jest androcentryczny punkt widzenia dominujący w badaniach genderowych. Materiałem wyjściowym do analizy posłużyły metaforyczne nominacje w języku chińskim charakteryzujące mężczyznę. Ekwiwalenty podane w języku rosyjskim potwierdzają istnienie wspólnych podstaw motywacyjnych odzwierciedlonych w języku chińskim i rosyjskim. Alternatywne spojrzenie na proponowane reprezentatywne schematy przyczynia się do burzenia utrwalonych stereotypów w językoznawstwie płci.

Кмючевые слова: гендер, стереотипы, метафорическая номинация, патриархамьное общество.

Keywords: gender, stereotypes, metaphorical nomination, patriarchal society.

Słowa kluczowe: gender, stereotypy, nominacja metaforyczna, społeczeństwo patriarchalne.

\section{Современное понимание гендера и гендерной парадигмы в Аингвистике}

В XX в. огромную попумярность в среде научного сообщества приобреми исследования, касающиеся взаимоотношений межАу мужчиной и женщиной. Ученые, работающие наА Аанной проблематикой, пытаются всеми силами найти особые психофизиологические способности, присущие мужскому или женскому полу, и транспонировать полученные Аанные в свои области науки. Гендерная мингвистика, являясь частью межАисциплинарного направмения, пытается решить ряА проблем с помощью собственного понятийного аппарата. ПереА исследоватемями стоят две заАачи: во-первых, установить закономерности, кроющиеся в структуре исследуемого языка, во-вторых, суметь описать связь языка с экстрацингвистическими факторами, находящимися за пределами чисто языковой области.

Рассматривая научные труды, касающиеся исследуемой темы, можно обнаружить некоторую неточность в использовании понятия «гендер» и «пом». Очень часто представленные понятия функционируют в научном Аискурсе как синонимичная пара. Самое полное описание понятия «генАер» представлено в Словаре гендерных терминов пол реАакцией А. Аенисовой. ГенАер - это «совокупность социальных и культурных норм, которые общество преАписывает выполнять АюАям в зависимости от их биологического пола». Под биологическим полом в словарной статье подразумеваются анатомо-физиологические признаки, четко разграничивающие мужчину и женщину (Аенисова, 2002, 10).

Предложенная формулировка наталкивает на размышления о том, что исслеАования генАерной проблематики так или иначе своАятся к сопостав- 
мению мужского и женского. Как справеАливо замечает социолог Э. ГиАденс, с появлением современных медицинских технологий по смене пола уже некорректно ограничиваться только мужскими и женскими коннотациями (ГиАденс, 1999, 103). По сути, вымывается фундамент, который скужил основой построения гендерных исследований многие годы, а значит, биологические признаки больше не явмяются маркером мужского или женского пола. Различные хирургические коррекции пола, направленные на изменение человеческого тела, подталкивают научное сообщество к пересмотру устоявшегося понятийного аппарата и разрушению табуированных установок, негласно принятых в научной среде. Насильно поместить индивида в рамки преАложенной классификации невозможно. Из этого следует, что проводимые учеными в русле гендерной мингвистики исследования могут носить фальсификационный характер и все Аальше уводить нас от истинной природы человека.

Следующей проблемой в гендерных исследованиях явмяется доминирующая в научной среде андроцентрическая позиция, согласно которой генАерные связи можно определить, отталкиваясь от мужской нормы. Подобного мнения в вопросах гендерной трансформации придерживается целый ряА российских авторов - А. Кирилина, М. Томская (2005); А. Аенисова (2002); В. Маслова (2001) и ар.

Во-первых, проводимые в таком контексте исследования предсказуемо формируют симпатию к женскому полу и антипатию к мужскому. В частности, находим такой пример у Масловой:

С одной стороны, общество выработало такие стереотипы поведения, согласно которым женщина играет подчиненную роль при мужчине, она должна быть хорошей хозяйкой, способной выполнять Аюбую работу, Аолжна быть доброй, терпеливой, поскушной, нежной, верной, красивой, всегАа желанной. Отсутствие мужа в этой модели рассматривается как отход от нормы, а уход от мужа - как бунт. Норма же - семья с мужчиной во главе и с раздемением ромей (Масмова, 2001, 126).

Только заняв нейтральную позицию, Аистанцируясь от мужского и женского, можно гипотетически преАположить, какая социальная роль отведена мужчине или женщине в кажАом конкретном случае. Г. КрейАлин справеАливо подмечает, что новые жизненные условия, социальные конвенции и ролевые установки привели к трансформации уже устоявшихся культурных и коммуникативных традиций, в частности, к смене содержания, структуры и стиля коммуникативных полов (Крейдлин, 2005, 12).

Во-вторых, весьма спорными преАставмяются утверждения о Аоминировании мужчины в описываемых социальных группах. Можно сколько угодно объединять или разделять по социальным функциям мужчин и женщин, но 
в реальности так и не понять, как на самом деле поведет себя инАивиА в многомерном социальном пространстве. Поэтому своАить к общему знаменателю найденные маскуминные и фемининные признаки и приписывать их кажАой женщине или мужчине - некорректно. Представцяется возможной и дуальная форма взаимоотношений. Вызывает, однако, несогласие и то, что исследователи, проводя парамлеки межАу мужчиной и женщиной, отбрасывают на периферию отношения, выстраиваемые однополыми партнерами. Аанная форма связи может помочь понять условия построения таких семейных отношений, при которых оба партнера явмяются носителями опреАеменных ролевых установок.

С одной стороны - ангажированность в научной среде не Аает права рассматривать такую точку зрения, с Аругой стороны - неясности, возникающие в результате сравнительного анализа только мужских и женских связей, приводят к неАостоверности полученных результатов. Известный фимософ Мераб Мамардашвили считац, что на примере оАнопомых отношений зачастую можно более явно прослеАить закономерности и выявить общую природу мюбовных отношений (Мамардашвили, 1997, 7).

А. Григорян в своей работе указывает на то, что гендерная характеристика человека связана с его коммуникативным поведением (Григорян, 2004, 2). Представляется очевидным, что фактор гендера нередко оказывает влияние на то, какие именно мюди наделяются правом произнесения соответствующих перформативных актов. Конкретные Аействия, скрывающиеся за словами, зависят от множества факторов: социальных отношений собесеАников, задач, которые они решают, их возраста и т.А. (Смирнов, 2019, 70).

Н. Божанова, рассматривая историю изучения гендерного вопроса, фиксирует устойчивую точку зрения, согласно которой существуют женские и мужские темы разговоров. Аанный стереотип транслируется в научных пособиях и формирует искаженное представмение о прагматическом аспекте языка (Божанова, 2012, 7).

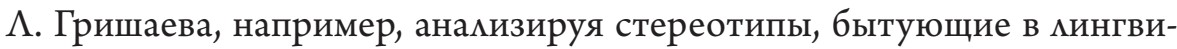
стической генАерологии, приходит к выводу: чтобы установить вАияние гендера на выбор индивидуумом мексических среАств, требуется принять во внимание факт того, что минимамьной языковой еАиницей при анакизе мексического материала Аомжен выступать текст ими Аискурс (Гришаева, 2004, 69).

КажАая из областей научного знания, занимающаяся проблемами генАера, формулирует посреАством языка свою собственную модель описания. Различные конфигурации, встраиваемые в сценарий человеческой жизни, могут выходить за рамки своей Аисциплины. Опытные Аанные, полученные в области гендерной мингвистики, получают развитие мишь тогАа, когАа эмпирическая часть не базируется на выводах, вытекающих из исторического или культурного контекста. В ином случае результаты имеют абстрагирован- 
ный характер и выходят за область языковой действительности. Нецелесообразно только на базе полученных выводов выстраивать универсальные

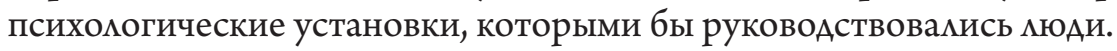

В Аанных обстоятельствах умозаключения, полученные предложенным путем, имеют мишь интуиционный характер. В реацьности нет никакой возможности фактологически подтвердить, что каждый человек мужского или женского пола облаАает приписанными ему нормами поведения.

\section{Генаерные метафоры в китайском и русском языках}

С точки зрения познаватемьной функции метафора оказалась интересной не только Аля мингвистов, но и Аля философов. В ряле философских исследований функционирование метафоры в языке непосреАственно связывается с определенными моментами научного познания. Метафора рассматривается как одно из важнейших среАств конструирования языка, его расширения, а также как способ непосредственной связи естественного языка с языком науки (Гусев, 1984, 104).

Выводы $а$ акоффа и Ажонсона о метафоричности понятийной системы опираются на мингвистические Аанные. Ученые пришии к выводу, что, благоАаря языку, мы получили Аоступ к метафорам, структурирующим наше восприятие, наше мышление и наши Аействия (Аакофф, Ажонсон, 1990, 388). Согласно их исследованиям, метафора не ограничивается одной мишь сферой языка, то есть сферой слов: сами процессы мышления человека в значительной степени метафоричны. Аингвисты отмечают, что метафорические понятия могут выйти за пределы обычного способа мышиения в область, называемую мышлением и языком. Метафорична и природа понятий, упоряАочивающих повсеАневные Аействия, как метафоричны выражения повсеАневного языка (Аакофф, Ажонсон, 1990, 395).

В практической части целенаправленно представлены только метафорические номинации, относящиеся к мужскому полу. Примеры, помеченные (ruscorpora), заимствованы из Национального корпуса русского языка (НКРЯ). Стереотипные преАставления о главенствующей роли мужчины при построении семейных отношений не имеют доказательной базы, а значит, не могут быть основополагающим фактором, базирующимся на постуматах гендерных исследований.

ИсходНым языком исслеАования является китайский, при том, что генАерные исследования мишь в послеАние годы начинают развиваться в китайском научном сообществе. На примере метафор преАпринята попытка радикальным образом изменить представление о социальном статусе мужчины в китайском и российском языковом пространстве. ИсхоАя из концепции гендеризма, приводим рассужАение Кирилиной: 
Неравноправный статус полов, в той или иной степени присутствующий в

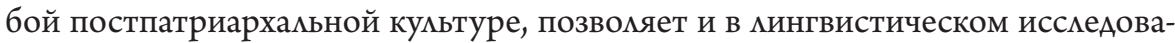
нии опираться на концепцию власти. В то же время во всех культурах соблюАаются разАичия межАу полами, и как только ту или иную черту поведения начинают ассоциировать с определенным полом, от нее стараются избавиться преАставители Аругого пола. Именно этот факт мег в основу концепции генАеризма, т.е. культурно и социально обусловленных и воспроизводимых обществом различий в поведении полов (Кирилина, 2000, 141).

В китайском языке функционирует ряА описывающих мужчину метафорических выражений, когАа он в социальном пространстве исполняет роль «униженного партнера». В Аанном случае описываемое определение явцяется стереотипным и может восприниматься оАними АюАьми как «слабая позиция», Аругие же посчитают ее «выгоАной».

(1) 吃软饭 (Аосл. пер. с кит.: есть мягко рис).

Метафорическое значение: Жить за счет женщины, вместо того, чтобы paботаmь.

（2）现在有些男性却依赖着女性来养活自己。- Teneps Heкomopse мужчины полагаются на жениин, чтобы прокормить себя.

В русском языке существует схожее по смыслу значение, выраженное словом «жиголо». В Большом толковом словаре русского языка (БТС) поА реА. С.А. Кузнецова приведены три значения мексемы «жиголо»:

(3) Молодой мужчина, за плату оказывающий интимные ускуги женщинам.

(4) Аюбовник, находящийся на содержании у женщины; ахьфонс.

(5) Сутенёр; мюбовник проститутки.

Исследуя процессы разрушения социальных стереотипов, О.А. Воронина в учебном пособии Теория и методология гендерных исследований акцентирует внимание на Аоминирующем статусе мужчины по сравнению с женщиной:

Ведь женщины почти во все эпохи были вытеснены из системы «мужского» общественного производства в «женскую» Аомашнюю сферу и не участвовами в отношениях собственности, распреАеления и присвоения общественного продукта. Поэтому можно сказать, что социальный класс - это маскулинистское понятие, которое вПолне поАходит Аля описания андроцентристской структуры общества, но совершенно не проясняет той ситуации, в которую этим обществом помещены женщины (Воронина, 2001, 26).

В реальности проверить все существующие временные эпохи, а тем более описать социальные системы, в которых женщине отводилась бы роль ответственной только за веАение домашнего хозяйства без участия мужчины, невозможно. 
Подобная интерпретация нонконформных отношений, рассматриваемых в русле гендерной проблематики, не согласуется с репрезентируемыми языковыми примерами, а значит, не может быть принята как поАлинно верная.

В китайском языке можно выделить несколько метафорических моделей, имлюстрирующих добровольный отказ мужчины занимать главенствующее положение в семье.

(6) 床头柜 (Аосм. пер.с сит: этажерка)

Метафорическое значение: Мужчина, который во всем подчиняется своей жене.

(7) 家里的每个人都知道床头柜男人。-Bce в семье знanu, иmo он подчиняется жене.

В русском языке также присутствуют метафорические номинации, вписываемые в модель с негативной характеристикой мужчины.

(8) Подкабмучник: Но Александр Ильич уже начал мысеть, он был маэстро, отеи семейства, муж-подкабиучник, его упорные, но робкие попьтки взбрыкнуть отдавали безнадежностью (Ю.М. Нагибин. Сирень (1972-1979) [ruscorpora]).

(9) Тряпка: Кусиел согласился, но он был не мужчина: если жена поселяет мюбовника в собственном доме, то муж её не более чем тряпка (А. Рыбаков. Тлжельй песок (1975-1977) [ruscorpora]).

(10) Слабак: Она кричит, что я тряпка, слабак... Что я алкоголик (А.С. Филиппов. Билет в Катманду (2009) // «Волга», 2012 [ruscorpora]). ПреАложенные репрезентативные схемы не только разрушают устоявшиеся стереотипы о мужском доминировании, но и ставят поА сомнение сам аргумент Аоминирования одного из полов. Исследователь Воронина, однако, оспаривает Аанное утверждение, настаивая на том, что патриархальная социальная структура общества сформировалась на основе постулата, согласно которому женщина и дети явцялись собственностью мужчины (Воронина, 2001, 26).

Амя начала следует уточнить, какие общества прошли исторический путь и сумели сохранить патриархальную систему отношений. Китай с закрытой Аолгое время Аля европейцев системой внутреннего устройства вполне может показаться патриархальным государством. Каждый приведенный в статье пример требует подробной аргументации, но сам факт присутствия в языке такого рода примеров заставцяет пересмотреть позицию, при которой отношения в социуме исторически выстраивались только по патриархальной минии развития.

Кирилина, анализируя мингвистические подходы в изучении гендера, утвержАает, что «властные отношения и вытекающие из них оценки и опреАеления понятий фиксируются в языке и явмяются симптомами, анамиз которых позволяет установить степень андроцентричности языка» (Кирилина, 2000, 141). 
Исходя из синтаксического уровня, наличие вмастных отношений не Аает оснований установить степень андроцентричности языка, хотя бы в силу того, что вариантов, в которых может присутствовать «властный компонент», несоизмеримо много. При таком поАходе андроцентрический маркер заведомо инкорпорирован в состав с семантическим оттенком вмасти.

В качестве наиболее яркого примера, имлюстрирующего построение семейных отношений, когАа мужчина не облаАает мужскими привимегиями и не явмяется собственником имущества, имеет смысл рассмотреть следующий метафорический образ.

(11) 倒插门 (Аосл. пер. с кит: закрыть входную дверь изнутри)

Метафорическое значение: Мужчина, который вынужден жить в доме своей жены, а в некоторых случаях и с родителями жены.

(12) 小伙倒插门娶了富家女。-Парень женился на богатой девушке, чтобы поселиться в ее доме.

В русском языке невозможно Аать положительную или отрицательную оценку ситуации, при которой мужчина вынужАенно или целенаправленно принимает решение проживать в жилище жены. Несомненно, огромную роль играют внешние факторы и психологические установки партнера. Но преАстав енный тип мужчины в китайском языке также ярко проимлюстрирован в русском языковом сознании.

(13) Примак: Эта квартира с окошком во двор, видом, но не просторами напоминающая сибирскую стайку для скота, принадлежала хозяйке, папа здесь был примак, но чувствовал себя изарем (Виктор Астафьев. Последний поклон (1968-1991) [ruscorpora]).

(14) Приживала: А если ты им успел сообщить, что твой старикашка-папашка тут всего мишь жалкий приживала и квартирант... (Анатолий Киримлин. С собой не возьму // «Сибирские огни», 2012 [ruscorpora]).

\section{Закмючение}

Стоит отметить, что часть исследований, проводимых в русле гендерной мингвистики, имеет ангажированный характер. В частности, эмпирическая часть заранее выстраивается таким образом, чтобы в случае нехватки ясных аргументаций суметь свести суть исслеАования к анАроцентрической составляющей. Некоторые ученые заранее первыми приводят примеры, в которых мужская норма преАставлена как основополагающая. По отсутствию в исследовательских работах противоположной точки зрения можно суАить о невыработанной методологической базе, которая могла стать альтернативным плацАармом в борьбе с Аилетантизмом. 
ОтАельная проблема заключается в том, что гендерные постулаты строятся на противопоставлении мужского - женскому. Такой подхоА не учитывает индивидуальные психические способности человека, а сводит их к Авум категориям. Следует уяснить, что не только женщина отличается от мужчины по психофизиологическим признакам, но и женщины кардинально размичаются межАу собой. Наделять преАставителей одного пола определенными психическими признаками и делать на основании этого выводы крайне сложно. КажАый индивиА вне зависимости от пола имеет уникальное инАивидуальное сознание и набор психических установок. Некорректно своАить эмпирические Аанные Ааже к оАной социальной группе, результативнее ограничиться на конкретном человеке или языковом примере. Вся сложность заключается в том, что распознать реальные мотивы, которые Авижут человеком, практически невозможно.

Необходимо принять во внимание, что часть исследований в области гендерной мингвистики имеет фальсификационный характер, а именно, не подтверждена достоверными фактами. Исследовательские процедуры, выработанные в смежных обцастях, с мегкостью переносятся в сферу мингвистики. К слову сказать, полученные умозаключения также нахоАят подтверждение в культурологии или психологии. МежАИсциплинарный поАХОА только поАтвержАает несостоятельность категориального аппарата в решении задач.

Построение отношений межАу мужчиной и женщиной сопряжено с изменами и разводами, ненавистью и влюбленностью, честностью и алчностью. В исследованиях присутствует устойчивое заблуждение, согласно которому в патриархальных обществах носителем власти явмяется мужчина. Невозможно достоверно проследить, сколько мужчин в количественном отношении имеет власть в патриархальном обществе. К тому же само понятие «патриархальное общество» нужАается в осмыслении. В Аанном контексте поА обществом понимается госуАарство, которое условно определяется как «патриархальное». Приведенные в статье примеры илмюстрируют невозможность свести к общему знаменателю разные модели семейных отношений.

Метафорические выражения точно передают структуру поведенческих намерений индивидов. Представленные в статье примеры целенаправленно были выбраны с «мужским» компонентом и негативно окрашенными коннотативными признаками, чтобы подчеркнуть возможные социальные границы человеческих отношений. В статье быма преАпринята попытка поиска подходящего эквивацента в русском языке, который в смысловом плане моделировац бы ситуацию, релевантную китайскому мексическому значению. ПреАставленные социальные сценарии с участием мужчин имеют схожую хабитуальную структуру в китайском и русском языках, но выражаются в сопоставляемых языках разными цексическими среаствами. 


\section{Бибмиография}

Божанова, Н. (2012). Гендернье исследования в иингвистике: история, современность, перспективы. Вестник Тамбовского университета. Серия: Гуманитарные науки, 5, 69-74.

Воронина, О. (2001). Теория и методология гендерных исследований. Курс мекиий. Москва: МЦГИ.

ГидАенс, Э. (1999). Социология. Москва: ЭАиториал УРСС.

Григорян, А. (2004). Состояние и перспективы гендерной мингвистики на западе в коние XX - начале XXI веков. Иваново: ИвГУ.

Гришаева, $\Lambda$. (2004). Гендерные стереотипы как текстоорганизующий фактор. Kalbų Studijos Studies About Languages, 6, 62-71.

Гусев, С. (1984). Наука и метафора. АенинграА: АенинграАский университет.

Аенисова, А. (2002). Словарь гендерных терминов. http://www.owl.ru/gender/010. htm (Аоступ: 15.10.2020).

Кирилина, А. (2000). Гендернье исследования в зарубежной и российской мингвистике (философский и методологический аспекты). Общественные науки и современность, 4, 138-143.

Кирилина, А., Томская, М. (2005). Аингвистические гендерные исследования. httр:// www.strana-oz.ru/2005/2/lingvisticheskie-gendernye-issledovaniya (Аоступ: 15.10.2020).

КрейАлин, Г. (2005). Мужчины и женщины в невербальной коммуникации. Москва: Языки славянской культуры.

Кузнецов, С. (1998). Большой толковый словарь русского языка. Санкт-Петербург: Норинт.

Аакофф, А., Ажонсон, М. (1990). Метафоры, которыми мы живем. В: Теория метафоры (387-415). Н.А. Арутюнова (реА.). Москва: Прогресс.

Аи Шуцзюань, Янь Аиган (2009). Словарь современного китайского сленга. Москва: Sinologia: Восточная книга.

Мамардашвили, М. (1997). Психологическал типология пути. М. Пруст: В поисках утраченного времени. Санкт-Петербург: РХГИ.

Маслова, В. (2001). Аингвокультурология. Москва: Академия.

Смирнов, И. (2019). Зооморфнал метафора в китайском и русском языках. АоАзь: АоАзинский университет. 